\title{
Dissociation of patterned alternation learning and the partial reinforcement extinction effect in preweanling rats
}

\author{
MARK STANTON \\ The University of Texas, Austin, Texas
}

\begin{abstract}
Sprague-Dawley rat pups aged 14 or 18 days were trained on a patterned (single) alternation schedule with either an 8- or a 105-sec intertrial interval (ITI). At the 8-sec ITI, alternation learning was obtained at both ages, but the older age group learned more rapidly. There was no evidence of response alternation at the 105-sec ITI at either age. Continuously reinforced (CRF) and partially reinforced (PRF) groups trained and extinguished along with the patterned alternation (PA) group at the 105-sec ITI showed a robust partial reinforcement extinction effect (PREE) at both ages. Moreover, there was no difference in the rate of extinction of the PRF and PA groups at either age (i.e., no effect of $\mathrm{N}$-length). A PREE can therefore be obtained in infant rats under conditions that apparently preclude the formation of sequential associations. The implications of this finding for the ontogeny of instrumental learning and extinction are discussed.
\end{abstract}

In recent years, this laboratory has begun an analysis of the ontogeny of instrumental reward learning and extinction. In reward learning, response strength in extinction is inversely, rather than directly, related to response strength in acquisition. This inverse property is demonstrated by a family of phenomena known as the "paradoxical effects" (Amsel \& Stanton, 1980). They are so named because historically they presented a paradox for classical associationist theories (e.g., Hull, 1943), but they present an equal paradox for modern ones (e.g., Rescorla \& Wagner, 1972). Included among the paradoxical effects are the partial reinforcement extinction effect (PREE)-faster extinction after continuous reward than after partial reward; the overtraining extinction effects (OEE)faster extinction with extended acquisition training; the magnitude of reward extinction effect (MREE) faster extinction with increasing reward magnitude; and successive negative contrast (SNC)-performance decrements below a low-reward baseline following shifts from high to low reward. In all of these effects, conditions which produce superior acquisition performance produce inferior performance when reward is subsequently withheld or, in the case of SNC, re-

This research constitutes a portion of the author's doctoral dissertation submitted to The University of Texas at Austin. It was supported by NIMH Grant MH-30778 to Abram Amsel. The author wishes to thank Dr. Amsel for his support and guidance throughout the course of this work and for criticisms of this manuscript. Thanks are also due Hussein Ahmed, Waylon Allen, and Will Schlotter, for technical assistance, and Sherri L. Evans, for assistance with preparation of the manuscript. Requests for reprints should be sent to: Mark Stanton, Department of Psychiatry and Behavioral Sciences, Stanford University School of Medicine, Stanford, California 94305. duced in magnitude. All of these effects contradict the view that response strength in extinction is a measure of associative strength in acquisition.

Our analysis of the ontogeny of reward learning has many parallels with the comparative analysis carried out by Bitterman, Gonzalez, and their colleagues (Bitterman, 1975; Gonzalez \& Champlin, 1974). During postnatal ontogeny in the rat, instrumental extinction undergoes a transition from being nonparadoxical to being paradoxical (Amsel \& Stanton, 1980). That is, early in ontogeny, response strength in extinction is directly related to response strength in acquisition, whereas later in ontogeny the reverse is true. Comparative work suggests the same transition in phylogeny. Beyond this general trend, however, we have found that the PREE appears much earlier in ontogeny than do other paradoxical effects. The PREE first appears at 12-14 days (Chen \& Amsel, 1980; Letz, Burdette, Gregg, Kittrell, \& Amsel, 1978), whereas the MREE fails to appears clearly until about 21 days (Burdette, Brake, Chen, \& Amsel, 1976; Chen, Gross, \& Amsel, 1981; Stanton, \& Amsel, 1980); SNC first appears at 25-26 days (Chen et al., 1981; Stanton \& Amsel, 1980); and there is no evidence of the OEE prior to 25-26 days (Amsel $\&$ Stanton, 1980). The sequence of appearance of these extinction effects remains to be explained by theories that attribute these effects to a common set of learning mechanisms.

Of the many theories of instrumental extinction, two have remained prominent (Mackintosh, 1974). One is Amsel's "frustration theory" (Amsel, 1958, 1962 , 1967), which postulates the aversiveness of (expected) reward omission, primary frustration, $R_{F}$, and the avoidance of such frustration through Pav- 
lovian conditioning, anticipatory or conditioned frustration, $r_{f}$, as the determinants of performance decrements in extinction. The crux of this account is that, during extinction, subjects are not only losing an association between the stimulus conditions and the instrumental response, but are gaining an association between the stimuli and primary frustration, an association responsible for avoidance responses that compete with the instrumental response established in acquisition. The other theory of extinction is Capaldi's $(1967,1971)$ "sequential theory," so named because trial sequences are deemed a critical determinant of instrumental performance. This theory postulates generalization decrement of trial aftereffect stimuli as the main determinant of paradoxical extinction. At the heart of this account is the assumption that, on any given learning trial, the stimulus aftereffect, carryover, or memory of the previous trial is present and contributes to the stimulus complex on the current trial. When reward conditions are changed, the stimulus is altered and learned performance declines via generalization decrement.

Most students of instrumental learning accept the explanatory value of both theories, but assign them to separate parametric domains. When trials are massed (separated by short ITIs), sequential theory is usually invoked, especially when reward is small and the number of conditioning trials are few. On the other hand, when many trials are given, and they are separated by extended periods (e.g., $24 \mathrm{~h}$ ) or interpolated activity (e.g., other kinds of conditioning trials), and reward magnitude is large, frustration theory is usually invoked (although it is also applicable at short ITIs). This is particularly true in the case of the PREE, the most intensely studied paradoxical effect. Thus, the "massed-trials PREE" and "spaced-trials PREE" are generally recognized as two empirically similar, but theoretically quite distinct, phenomena (Amsel, 1967; Bitterman, 1975; Gonzalez, Fernhoff, \& David, 1973; Gray, Owens, Davis, \& Feldon, 1980; Mackintosh, 1974).

The ontogenetic dissociation between the PREE, on the one hand, and SNC and the MREE on the other, is reminiscent of what is found in phylogeny. The fish and turtle fail to show any of the paradoxical effects when trials are spaced (e.g., 24-h ITI). However, the PREE has been shown in these species when trials are massed (e.g., 30-sec ITI). This has led to the suggestion (Bitterman, 1975) that the spacedtrials PREE and paradoxical extinction following continuous reward (e.g., MREE, OEE, and SNC) are mediated by a common mechanism (e.g., frustration or "contrast"), one that is distinct from that producing the massed-trials PREE (carryover). A similar dissociation was found in a study of longterm memory employing rats as subjects (Gonzalez et al., 1973). When different retention intervals $(1$, 26,42 , and 68 days) were imposed between acquisi- tion and extinction, the spaced-trials PREE, the MREE, and SNC all disappeared as the retention interval increased, whereas the massed-trials PREE remained even at the longest retention interval.

These data suggest an explanation for the ontogenetic dissociation of the paradoxical effects, namely that sequential mechanisms are present at an age when conditioned-frustration expectancy mechanisms apparently are not yet operating. If the infant (12-14 days) PREE, like the fish PREE, is based on associations of trial sequences, whereas the laterappearing (weaning-age) paradoxical effects (OEE, MREE, SNC) depend on learned expectancies of reward and anticipated frustration, then simple patterned (single) alternation (PA), a kind of learning that directly depends on sequential associations and which can be shown in fish (Couvillon \& Bitterman, 1981; Gonzalez, 1972), should be present in infant rats at the age when the PREE is shown.

Stanton, Dailey, and Amsel (1980) have shown that 11- and 14-day-old rats can indeed learn patterned alternation under a variety of conditions when trials are separated by $8 \mathrm{sec}$. The conditions which supported PA in this study ruled out nonassociative interpretations of the carryover effect as well as the possibility that this carryover was necessarily some peripheral trial aftereffect, such as milk traces in the mouth or a lingering maternal odor. This finding provisionally supports the above-mentioned explanation of the ontogenetically earlier appearance of the PREE relative to the other paradoxical effects.

If the PREE at these early ages is of the massedtrials variety, it should be present under trial-spacing conditions which support PA and disappear when ITI conditions eliminate PA. The present study tested this prediction in rat pups 14-16 and 18-20 days of age. These ages represent a period in ontogeny when the PREE is clearly present (Amsel, 1979) but when many of the other paradoxical effects have not yet emerged (Amsel \& Stanton, 1980). At each of these ages, subjects received patterned alternation training with either massed or spaced trials. Since no evidence of PA learning was obtained with spaced trials, CRF and PRF groups were also trained and extinguished under the spaced-trial conditions in order to determine whether or not a PREE would appear.

\section{METHOD}

\section{Subjects}

Sixty-four male and female rat pups derived from 22 litters served as subjects. Half were 14 and half were 18 days of age at the start of training. At the time of deprivation, the 14-day-olds weighed a mean of $37.8 \mathrm{~g}$ (range $=34.5-43.9 \mathrm{~g}$ ) and the 18-day-olds weighed a mean of $42.6 \mathrm{~g}$ (range $=38.3-49.0 \mathrm{~g}$ ). Litters were housed in $48 \times 27 \times 20 \mathrm{~cm}$ plastic cages, continuously supplied with Purina Rat Chow and tap water. The lab was illuminated from 0800 to $2200 \mathrm{~h}$. The age of a litter was determined by checking for births during this illuminated period and designating the 
date of birth as Day 0. Litters were culled to eight pups (four males and four females) on the 3rd postpartum day. Litters were then left undisturbed until pups were selected as experimental subjects.

\section{Apparatus}

The apparatus was similar to, but somewhat larger than, the one used by Stanton et al. (1980). It was a Plexiglas runway with a $13 \times 7.5 \times 12 \mathrm{~cm}$ startbox, a $7.5 \times 12 \mathrm{~cm}$ alley of adjustable length, and $23.5 \times 25 \times 12 \mathrm{~cm}$ goalbox. Two manually operated sliding doors made of opaque Plexiglas separated the startbox from the alley and the alley from the goalbox. The goalbox was bisected into an $8.5 \times 25 \times 12 \mathrm{~cm}$ front chamber and a $15 \times 25 \times$ $12 \mathrm{~cm}$ rear chamber by an opaque Plexiglas gate. Attached to the rear wall of the goalbox was an electric exhaust fan (115 V, 50/ $60 \mathrm{~Hz}, 10 \mathrm{~cm}$ in diam) that expelled the dam's odors into a segment of dryer hose and out of the laboratory. The subjects spent the period between trials in $11.5 \times 11.5 \times 17 \mathrm{~cm}$ Plexiglas "ITI boxes" located near the runway. It was possible to warm the floor surface of the runway with commercial electric heating pads. Black posterboard panels, attached to the outside walls of the runway, prevented the older subjects, whose eyes had opened, from being distracted visually by events outside the apparatus. Three photocell circuits allowed latency measures in three alley segments (start, run, and goal) of equal length. When running the 14-day-olds, the length of the alley was $39 \mathrm{~cm}$ (three $13-\mathrm{cm}$ segments), and, because the ability to thermoregulate is just emerging at this age, the alley floor was heated to $31^{\circ}-33^{\circ} \mathrm{C}$. For the 18-day-olds, the floor was room temperature and the alley was $60 \mathrm{~cm}$ long (three 20-cm segments).

\section{Design}

At each age, four groups were formed to create a total of eight groups $(\mathbf{N}=8$ per group, with the exception of the 18-day-old Group PRF-105, from which one subject was discarded because of accidental injury). The four groups within each age consisted of Group PA-8, which was run on a patterned alternation schedule at an 8-sec ITI, and Groups PA-105, PRF-105, and CRF-105, which were run, respectively, on PA, partial reinforcement, and continuous reinforcement schedules, all at 105 -sec ITI. The PA schedule was RNRNRN . . . . In the PRF condition, the schedule of rewards (R) and nonrewards (N) was RRNNRNRRNNRRRNNNRNNR NNRRNNRRRNNRNRRRNNRR NNRRRNNRNRRNNNRNRRNR NNNRRRNRRNRNNRRNNNRR RNNRNNNRRRNRRNNNRRRN NRRNRRRNNNRRNNRNRNNR.

Combined across the two ages, the eight groups formed two overlapping factorial designs. One was a $2 \times 2$ design involving the four PA groups that assessed the effect of age (14 vs. 18 days) and ITI (8 vs. $105 \mathrm{sec}$ ) on PA learning in acquisition. The other was a $2 \times 3$ design that assessed the effect of age (14 vs. 18 days) and schedule (CRF vs. PRF vs. PA) on runway acquisition and extinction at the 105-sec ITI. Six 20-trial sessions (10 rewarded and 10 nonrewarded trials per session) were administered, three sessions per day over each of 2 days. Daily sessions occurred in the morning, afternoon, and evening and were separated by 3.5 to 4.5-h intervals. On the day following the 2 acquisition days, Groups CRF-105, PRF-105, and PA-105 received two extinction sessions, one in the morning and one in the afternoon. The procedure was the same as in the previous acquisition sessions except that all trials were nonrewarded and no priming reinforcements (see below) were given before the last session in order to avoid reinstating a reward expectancy once extinction testing had begun.

\section{Deprivation and Cannulation}

Approximately $24 \mathrm{~h}$ prior to the start of training, pups were taken from their nests, weighed to the nearest $0.1 \mathrm{~g}$, and placed individually in $14 \times 10 \times 14.5 \mathrm{~cm}$ compartments of a Plexiglas holding box. For the 14-day-old subjects, this box was heated to $33^{\circ} \mathrm{C}$ by electric heating pads. Approximately $12 \mathrm{~h}$ later, the subjects were fitted with oral cannulas. An extensive description of the cannulation procedure can be found in Hall and Rosenblatt (1977). Following the 2-3 $\mathrm{min}$ required to install their cannulas, the subjects were returned to their individual compartments until the start of training on the following day.

\section{Training Procedure}

About 20-30 min before the start of a training session, a lactating dam was anesthetized with an ip injection of Nembutal $(32.5 \mathrm{mg} / \mathrm{kg}$, Abbott Laboratories) and returned to her young so that her nipples would be moist and well suckled at the start of the session. Anesthesia was maintained with supplementary doses as necessary. At the start of training, pups had their bladders voided and were weighed. They were then placed in the goalbox and given three "priming" reinforcements to ensure reliable nipple attachment prior to the start of training. Reinforcement consisted of a 30-sec period of suckling on the anesthesized dam plus infusion of light cream. Infusions were performed with an infusion pump (Harvard Model 906) to ensure that the rate and duration of infusions were constant from trial to trial. The infusion rate was $.00625 \mathrm{ml} / \mathrm{sec}$. The duration, and hence the quantity, of the infusion varied from 5 to $8 \mathrm{sec}$ according to the age of the subjects: $.05 \mathrm{cc}$ in an 8-sec period for 18-day-olds, and $.03 \mathrm{ml}$ in $5 \mathrm{sec}$ for 14-day-olds. Reward magnitude was "equated" across age in the sense that all subjects received a reward approximately equal to .001 for every gram of body weight. The approximately $20 \mathrm{sec}$ of suckling that a subject was allowed following infusion was sufficient to completely empty the pup's cannula of milk.

Following these priming reinforcements, the subject was placed in a holding or "ITI" box, where it remained for the duration of the ITI. The first training trial then began with placement of the subject in the startbox. When the animal oriented toward the startbox gate, the gate was opened. This automatically started a photoelectric timer circuit, yielding three approach latencies (start, run, and goal), which stopped when the pup crossed the last photobeam at the entrance to the goalbox. At this instant, the gate bisecting the goalbox was raised on rewarded trials, making the dam available for attachment and the 30 -sec bout of suckling/ milk-infusion. On nonrewarded trials, the gate was not raised and the pup was detained for $30 \mathrm{sec}$ without access to the dam. On both kinds of trials, the goalbox door was closed to prevent retracing back into the alleyway. The pup was then returned to the ITI box. This cycle was repeated until all of a session's trials were run. The subject was then taken from the apparatus, weighed, and returned to its individual holding compartment until the start of the next session. In subsequent sessions, one (rather than three) priming reinforcement was given at the start of the session (excluding the last extinction session; see above).

Replications, using three or four littermates, were run at each age until all groups contained eight subjects. Littermates were assigned to different groups: the three 105-sec ITI groups when three littermates were run, and the PA-8 group as well when four littermates were run. In this way, all of the subjects in Groups CRF-105, PRF-105, and PA-105, along with about half of those in Group PA-8, were derived from the same eight litters. The balance of the subjects in Group PA-8 were taken from as many different litters as possible. At 18 days of age, a total of seven litters went into Group PA-8. At 14 days of age, six litters went into Group PA-8.

Subjects in the three 105-sec ITI groups were run as a squad and in rotation, each of the three subjects receiving a given trial before going on to the next trial. The ITI, therefore, was determined by the time taken to run two subjects and averaged $105 \mathrm{sec}$ with a range of $\pm 15 \mathrm{sec}$. Since each of the subjects in a squad received a different schedule, the PA subject could not anticipate trial outcomes on the basis of cues associated with the treatment of its squad mates. The order of running these subjects was counterbalanced as closely as possible across the eight replications. Subjects assigned to the PA-8 condition were run individually rather than in rotation. On half the occasions, they were run immediately before and on the other half immediately after the squad of subjects run at the 105-sec ITI. 
At the end of each session, the pups were taken to an adjacent room for postfeeding on the nipple, which was intended to equate, at the end of each session, the different groups for total diet consumed. Group CRF received one reward during postfeeding. The other groups received a quantity of diet equivalent to 11 rewards: 1 reward plus the additional 10 rewards received only by Group CRF during the training session. Following the last session of the day (the third and sixth sessions), all subjects received (at least) an additional $1.0 \mathrm{ml}$ of diet. This caused the overnight weight loss to be about the same as between daily sessions.

\section{RESULTS}

This study addressed two questions. One was the effect of ITI on PA learning. The other was the pattern of acquisition and extinction found among the groups trained at the 105-sec ITI. These questions were addressed in separate analyses of variance.

\section{Acquisition of Patterned Alternation}

The approach speeds in acquisition of Groups PA-8 and PA-105 are shown in Figure 1. Data from the start, run, and goal segments were essentially the same, so approach speeds are shown for the total alley. There was no PA learning at either age when the ITI was $105 \mathrm{sec}$. At the 8-sec ITI, alternation learning was more pronounced in the older animals. Performance at each age was analyzed in a separate analysis of variance between the error variances of the two ages were not sufficiently homogeneous. This lack of homogeneity is an artifact of locomotor maturation. These ANOVAs contained the between-subjects factor of ITI, and the within-subjects factors of blocks and reward.

18- to 19-day-olds. The upper panel of Figure 1 shows characteristic PA learning in 18- to 19-dayolds at the 8-sec ITI but no evidence of such learning at the 105-sec ITI. All curves showed a general increase in speed through midtraining, at which point there was a clear decline in the $\mathrm{N}$-trial curve of Group PA-8 only. This was reflected statistically by an interaction of ITI $\times$ blocks $\times$ reward $[F(11,154)=$ $15.41, \mathrm{p}<.001]$. Newman-Keuls analysis of this interaction indicated that, on the eighth and subsequent blocks of training, responding to nonreward at the 8-sec ITI was significantly $(p<.01)$ suppressed relative to the other three conditions, which did not differ from one another. The decline in the speed of running to nonreward in Group PA-8 from midtraining (Blocks 3-7) to the end of training (Block 12) was significant $(p<.01)$. Running speed to reward in Group PA-8 appeared slightly elevated above that to both reward and nonreward in Group PA-105 on the last few blocks of training, but this elevation was not significant $(\mathrm{p}>.05)$.

14- to 15-day-olds. The results for the 14- to 15day-olds appear in the lower panel of Figure 1. Here there was again no evidence of patterned alternation at the 105-sec ITI, coupled with an alternation effect

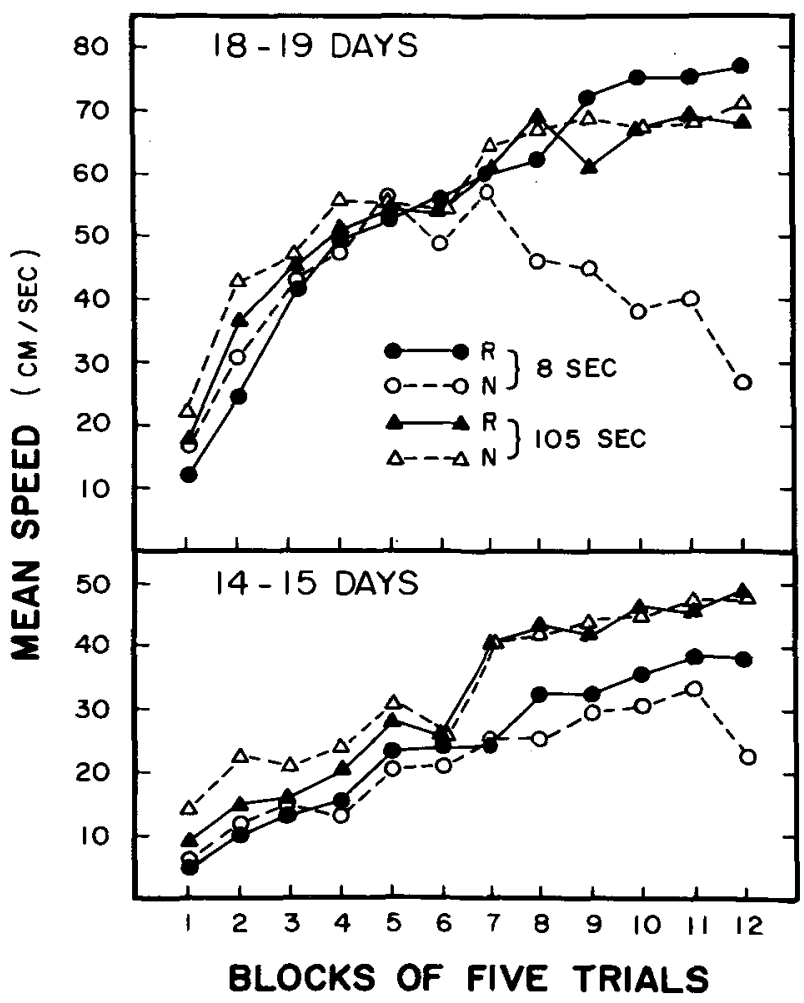

Figure 1. Mean alley speeds of the four groups that were given acquisition training on a patterned-alternation schedule. The upper panel shows speed of running on rewarded (R) and nonrewarded (N) five-trial blocks for the groups trained on Days 18 and 19 with an 8 -sec (circles) versus a 105-sec (triangles) ITI. The lower panel shows the same data for groups trained on Postpartum Days 14 and 15.

at the 8-sec ITI [ITI $\times$ blocks $\times$ reward, $F(11,154)$ $=2.43, p=.008$ ]. Performance at 14-15 days of age differed from that at 18-19 days, however, in that Group PA-8 appeared to show a weaker differential response and lower asymptotic running speeds relative to Group PA-105. Newman-Keuls analysis of the ITI $\times$ blocks $\times$ reward interaction established a significant $(p<.01)$ effect of reward only in Group PA-8 on the last block of training. This is considerably later than it was at 18-19 days, in which case the reward effect was significant by the eighth block of training. The decrease in nonrewarded responding of Group PA-8 also occurred later in the younger animals: Block 11 versus Block $12(p<.01)$ as opposed to Block 7 versus Block 8. The slower speed of running to reward of Group PA-8 relative to Group PA-105 was first significant $(p<.01)$ on the seventh block of training. This response suppression on rewarded trials may mean that the smaller alternation effect at 14-15 days resulted from "generalization of inhibition" from nonrewarded to rewarded trials. This would explain its appearance late in training, the point at which inhibition begins to gain strength. 
To summarize the data in Figure 1 as a whole, there was no evidence of PA at either age at the 105sec ITI. At the 8-sec ITI, PA was present at both ages, but the effect was much larger in the older animals. The small size of the effect at 14-15 days is surprising in that it contrasts with the large patterning effect shown by 14-day-olds in earlier studies (Stanton, 1982; Stanton et al., 1980). The major procedural difference between the present experiment and the earlier ones was the distribution of trials into sessions. The earlier studies employed three sessions of 40 trials each, whereas the present experiment employed six sessions of 20 trials each. It is reasonable to assume that, relative to the earlier experiments, the conditions of the present experiment increase the role of between-sessions retention (long-term memory) in PA learning. Impairment of long-term memory in infant rats is well documented (Campbell \& Spear, 1972), and this may explain why the alternation effect at 14-15 days of age in the present experiment was less dramatic than that found previously. In any case, the present report is consistent with the earlier ones in that, under a given set of conditions, PA learning improves with age.

\section{Acquisition at 105-sec ITI}

Figure 2 shows performance of Groups CRF-105, PRF-105, and PA-105 (referred to as CRF, PRF, and PA in this discussion). At each age, these data were analyzed by means of a groups $\times$ sessions ANOVA.

14- to 15-day-olds. At 14-15 days of age, acquisition of the running response was confirmed in all measures by a main effect of sessions $[F(5,105)=$ 111.85 (start), 251.07 (run), and 162.64 (goal); all ps $<.001]$. There were no group differences in acquisition. The groups main effect and groups $\times$ session interaction were not significant in any measure.

18- to 19-day-olds. At 18-19 days of age, acquisition of running produced, in all measures, a sessions main effect $[F(5,100)=86.97$ (start), 204.35 (run), and 78.01 (goal); all ps < .001]. In the start measure there were no significant group differences or interactions. In the run measure, there was no main effect of groups, but the groups $\times$ session interaction was significant $[F(10,100)=2.08, p=.033]$. NewmanKeuls tests revealed a significant $(p<.01)$ difference between Groups PRF and CRF in the first session. There were no significant group differences in any of the remaining sessions. In the goal measure, Groups PA and PRF ran more slowly than Group CRF $[F(2,20)=7.40, p=.004]$. Newman-Keuls tests showed that Group CRF differed from both Group PA $(p<.05)$ and Group PRF $(p<.01)$. These latter two groups did not differ.

\section{Extinction at 105-sec ITI}

Running speeds in extinction are plotted in the six panels of Figure 3, which follows the same format

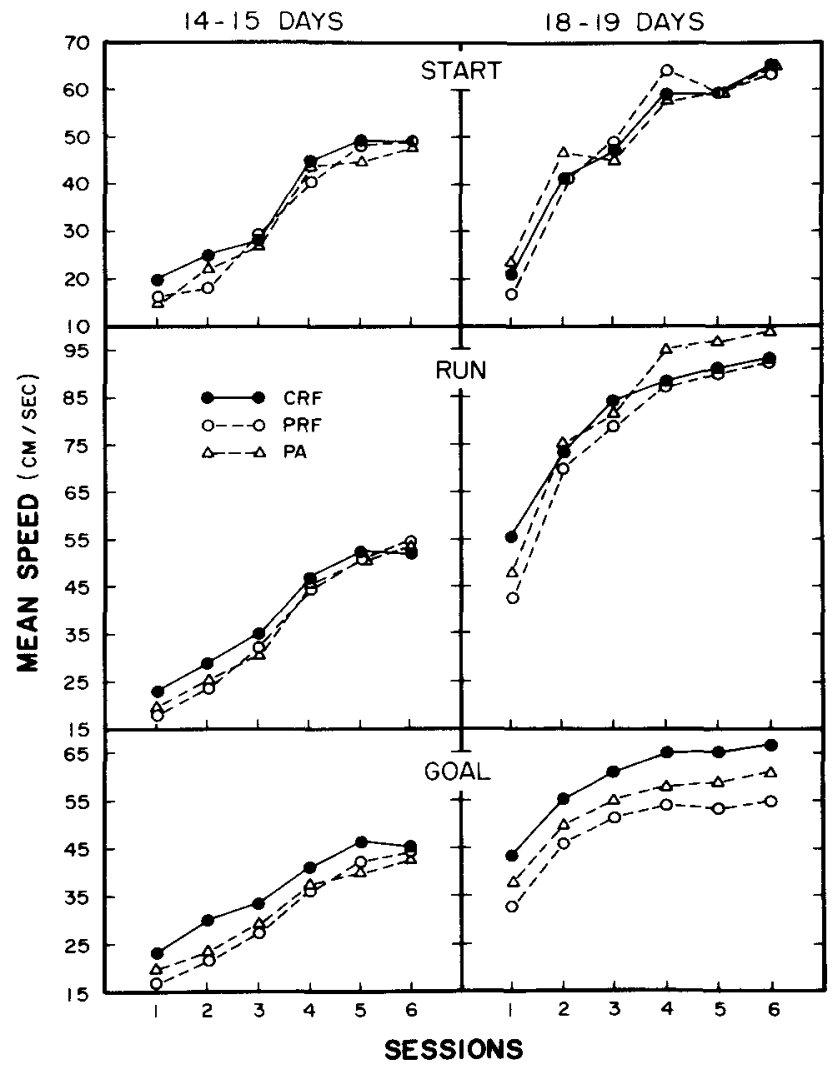

Figure 2. Mean acquisition alley speeds of the six groups trained at the 105-sec ITI. At each age (14-15 days in the left panels and 18-19 days in the right panels), independent groups were trained on continuous (CRF), partial (PRF), and patterned alternation (PA) reward schedules. Data points represent 20-trial sessions. The upper, middle, and lower panels show performance in start, run, and goal segments of the runway, respectively.

as Figure 2. The two ages and the three alley segments were each analyzed by an ANOVA involving the between-subjects factor of groups (CRF, PRF, and PA) and the within-subjects factors of sessions and blocks within sessions.

16-day-olds. At 16 days of age, there were no significant group differences in any measure on the last block of acquisition. The PREE was evident in all three alley segments: Group CRF extinguished at a faster rate than Group PRF or Group PA. The PREE was confirmed statistically by a groups $\times$ blocks interaction $[F(6,63)=5.23, \mathrm{p}<.001$ (start); $F(6,63)$ $=3.98, \mathrm{p}=.002$ (run); and $\mathrm{F}(6,63)=4.90, \mathrm{p}<.001$ (goal)]. Newman-Keuls tests of this interaction showed it to be, in all measures, the result of a blocks effect in Group CRF coupled with the absence of a blocks effect in Groups PA and PRF. Accordingly, the groups effect, which was absent on the first block, became substantial on subsequent blocks. There were small differences in this general pattern in the different measures. In the start measure, the decline in CRF speeds $(p<.01)$ and consequential groups effect $(p<.01)$ occurred between the first and second blocks. 


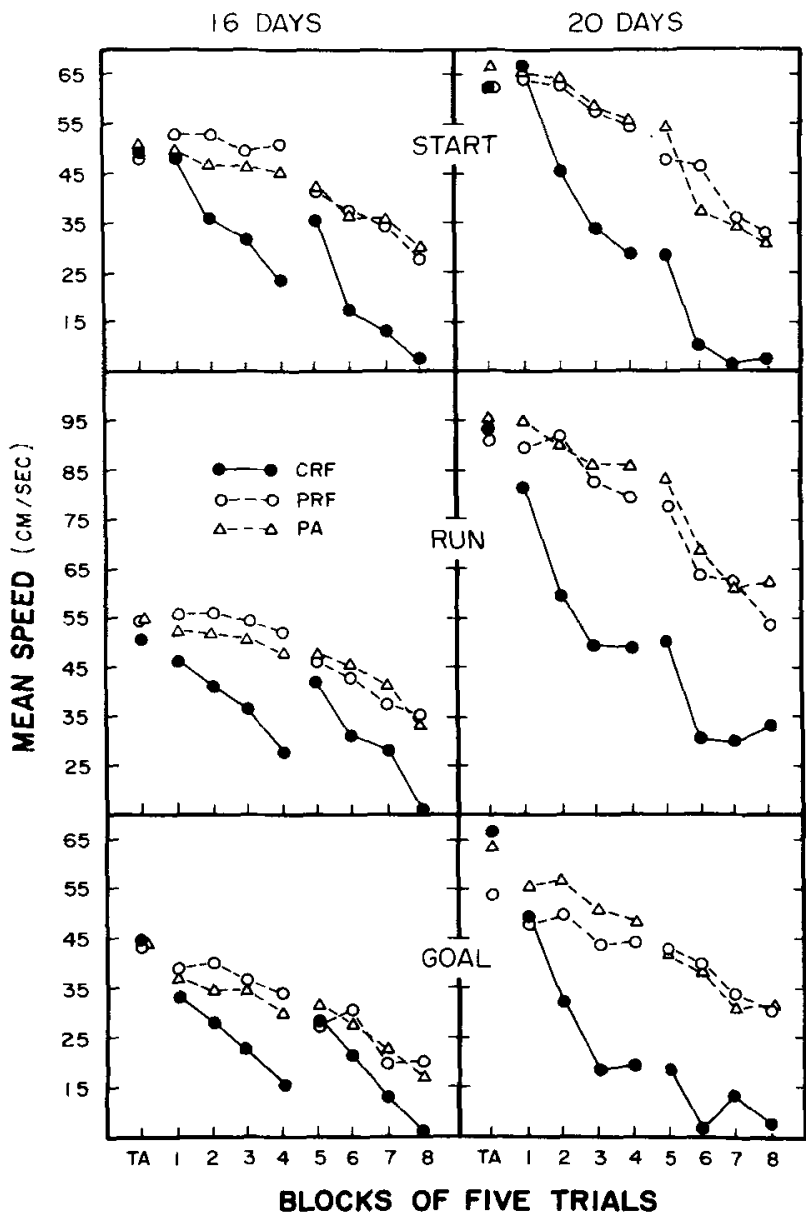

Figure 3. Mean extinction alley speeds of the six groups trained at the 105-sec ITI. Data points represent five-trial blocks. The leftmost point shows performance on the last block of acquisition ("terminal acquisition," TA). The next eight data points correspond to the two four-block sessions of extinction. Other details are as in Figure 2.

In the run measure, this same transition was not reliable (ps $<.01$ ) until the fourth block, although the groups effect was marginal $(p<.06)$ by the third block. In neither the start nor run measure did Groups PRF and PA ever differ, nor did they decline significantly. In the goal measure, however, the running speeds of all three groups declined reliably, Group CRF $(p<.01)$ by Block 3 and Groups PRF $(p<.05)$ and PA $(p<.01)$ by Block 4 . Still, the groups effect was reliable $(p<.05)$ by the second block and Groups PA and PRF failed to differ on any block. Clearly, and in all measures, Group CRF showed a faster decline in running speeds across blocks than did Groups PRF and PA. The absence of a groups $\times$ sessions $\times$ blocks interaction $[F<1$ in all measures] implies that this outcome obtained in both extinction sessions.

20-day-olds. At 20 days of age, there were no group differences on the last block of acquisition in the start and run measures. In the goal measure, how- ever, Group PRF ran significantly more slowly (p $<$ .05) than did Groups CRF and PA, which did not differ $(p>.05)$. The pattern of extinction at 20 days of age resembled that of the 16-day-olds: a PREE was present in all alley measures [groups main effect, $F(2,20)=10.55$ (start), 16.29 (run), and 29.98 (goal), and all ps < .001; groups $\times$ blocks interaction, $F(6,60)$ $=3.28, p<.007$ (start), and $F(6,60)=3.59, p=.004$ (goal)]. (The groups $\times$ blocks interaction fell short of significance in the run measure.)

Post hoc tests showed that in all measures, the groups effect was attributable to the lower speeds (p $<.01$ ) of Group CRF relative to Groups PRF and PA, which did not differ. In the start measure, the groups $x$ blocks interaction was brought about by Group CRF's significant $(p<.01)$ decline in responding from the first to the second block. This decline did not occur in Groups PRF and PA. In the goal measure, Group CRF was, again, the only group whose speeds declined significantly $(p<.01)$ across blocks. The groups effect (CRF vs. PRF and PA), however, was already reliable $(p<.01)$ in the first block. This suggests that the PREE occurred somewhat sooner in the goal measure than it did in the other measures.

A significant groups $\times$ sessions $\times$ blocks interaction $[F(6,60)=3.59, p=.004]$ was also found in the goal measure. This was a result of a groups effect that emerged across blocks in the first session but was present $(p<.01)$ on all blocks in the second session. The failure to obtain this interaction in the start and run measures could be attributable to the size of the error variance in those measures-1.5 to 2 times larger than it was in the goal measure.

In summary, a PREE was found at both ages and in all three measures. Moreover, there was no evidence at either age for an effect of N-length. At no point in extinction did Groups PA and PRF differ significantly in their level of responding or rate of decline in responding. The absence of an $\mathrm{N}$-length effect further supports the conclusion that, with an ITI of $105 \mathrm{sec}$, the memory or aftereffects of the preceding trial are not available to these young animals. This is in accord with the failure of Group PA-105 to show patterned responding in acquisition.

In addition to the similarities, it is worth considering the age differences shown in Figure 3. The younger animals differ from the older ones in two respects. First, the rate of extinction of Group CRF appears to be lower at 16 days. Second, Group CRF shows much more "spontaneous recovery" of responding between the two extinction sessions at 16 days than it does at 20 days of age. This age difference is difficult to assess directly, however, because locomotor maturation causes the two ages to differ in asymptotic running speed. Locomotor maturation does not produce differences in retrace behavior, however, and it is therefore possible to compare the performance of the two ages directly with this depen- 
dent measure. This dependent measure is of additional value because retracing is conventionally thought to represent frustration-induced avoidance of the goalbox during extinction (e.g., Birch, 1961; Ison, 1962).

\section{Retrace Measure}

Figure 4 plots the performance of the three 105sec ITI groups obtained with the retrace measure. Number of retraces on each trial was the number of times the subject locomoted toward and then away from the goalbox before making the criterion response. "Locomotion" was defined as movement of all four limbs. Pivoting back and forth on the hindlimbs was not counted as retracing. Acquisition and extinction were analyzed in separate analyses of variance involving the between-subjects factors of age and groups and the within-subjects factors of sessions (in acquisition) and of sessions and blocks (in extinction).

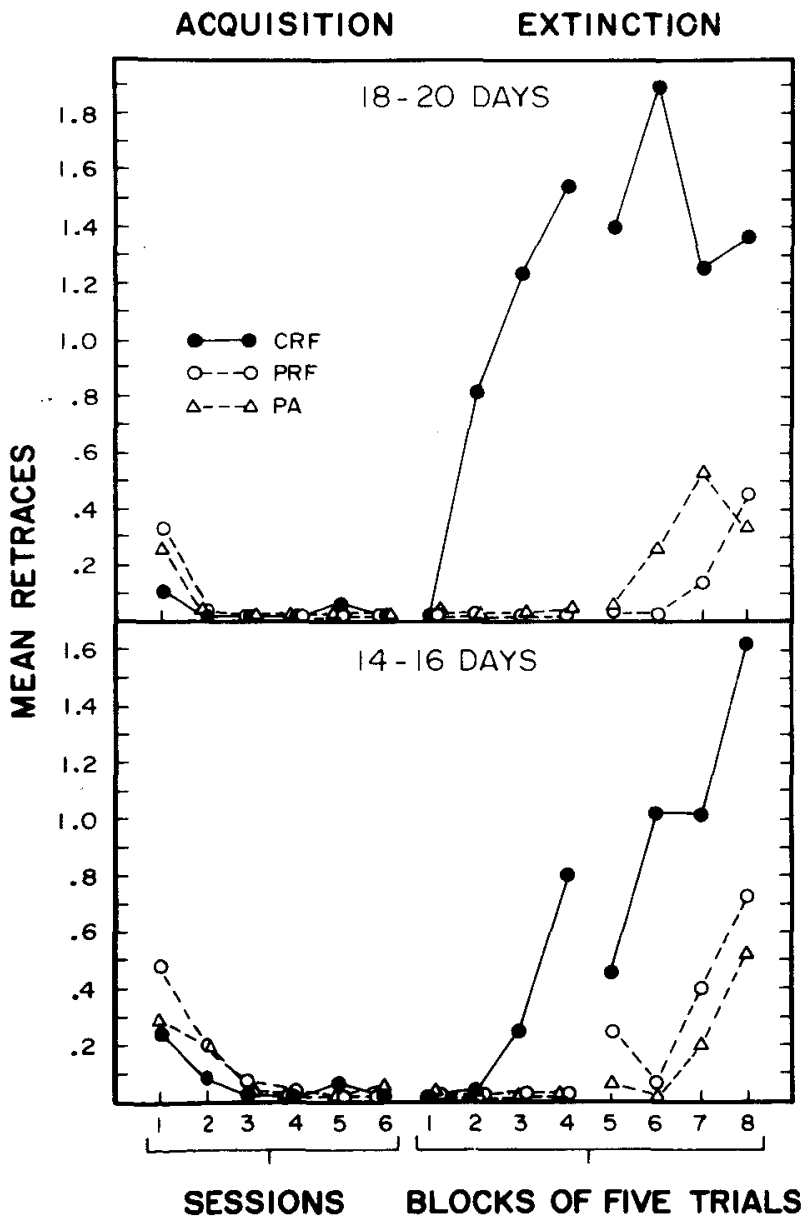

Figure 4. Mean retraces of the six groups trained with a 105 sec ITI. Acquisition performance is plotted in 20-trial sessions and appears on the left. Extinction performance is plotted in blocks of five trials, four blocks in each of two sescions, and appears on the right. The upper panel shows acquisition on Days 18 and 19 and extinction on Day 20. The lower panel shows acquisition on Days 14 and 15 and extinction on Day 16.
Acquisition. All subjects retraced less and less over the course of acquisition sessions $[F(5,205)=58.32$, $\mathrm{p}<.001]$. The younger animals retraced more than the older animals $[F(1,41)=8.13, p=.007]$, but only in the first two sessions $(p<.01)$. Subsequently, the two ages did not differ $(p>.05$; age $\times$ sessions interaction, $F(5,205)=3.68, p=.003$ ] . There were also group differences in the level of retracing, but only in the first acquisition session [groups $\times$ sessions, $F(10,205)=3.36$, $p<.001]$. Newman-Keuls tests showed that all groups differed from one another $(p<.01)$ in the first session.

Extinction. At both ages, a PREE was indicated by the elevated retracing (stronger response suppression) of Group CRF relative to Groups PRF and PA. Also, retracing in Group CRF increased with age. The increase in retracing across and within sessions was supported statistically by significant main effects of sessions $[F(1,41)=27.35, p<.001]$ and blocks $[F(3,123)=17.03, p<.001]$. The statistical reliability of the PREE was established by an interaction of groups $\times$ sessions $\times$ blocks $[F(6,123)=3.40, p=$ .004]. Newman-Keuls tests showed that this interaction resulted from Group CRF's increase in retracing across blocks in both sessions $(p<.01$ first session; $p<.05$ second session) coupled with the lack of a significant increase in Groups PRF and PA $(p>.05)$. Group CRF therefore differed $(p<.01)$ from both Groups PRF and PA, which did not differ $(p>.05)$. This groups effect $(p<.01)$ emerged only on the third block of Session 1, but was present on all blocks of Session 2.

A significant age $\times$ groups interaction $[F(2,41)=$ $7.20, p=.002]$ confirmed the increase with age in the size of the PREE. There were no differences $(p>$ $.05)$ between Groups PRF and PA at either age and no age differences involving these groups. At the same time, these groups, at each age, differed $(p<$ .01) from Group CRF, and the older CRF group retraced significantly more $(p<.01)$ than the younger CRF group. There was also a nearly significant interaction of age $\times$ groups $\times$ sessions $\times$ blocks $[F(6,123)$ $=2.13, p=.054$ ], suggesting that the groups $\times$ sessions $\times$ blocks interaction depended on age.

The retrace data thus demonstrate that the size of the PREE increases with age because of a corresponding increase in the rate of extinction following CRF training. Still, at both ages, a clear PREE was obtained under trial-spacing conditions that supported neither a patterning effect in acquisition nor an $\mathrm{N}$-length effect in extinction. This same pattern of results has been shown when running speeds in extinction are expressed as proportions of running speed on the last block of acquisition (Stanton, 1981).

\section{DISCUSSION}

A summary of the results of this study is as follows: (1) Rat pups at both 14-15 and 18-19 days of 
age learned PA when trials were separated by $8 \mathrm{sec}$ but not when they were separated by $105 \mathrm{sec}$. (2) The failure to obtain, at either age, evidence of intertrial memories spanning a 105-sec ITI in acquisition was corroborated by the failure to obtain an effect of $\mathrm{N}$ length in extinction. (3) In spite of the absence of these effects at the 105-sec ITI, a clear PREE was obtained at both ages, although the PREE became larger with age because of an increased rate of extinction following CRF training.

A dissociation between PA and the PREE does not, by itself, rule out the possibility that the PREE is based on sequential mechanisms. It is logically possible that PA fails to occur because animals can use aftereffect stimuli from previous nonrewarded trials but not from previcus rewarded trials. Since the PREE depends on carryover only from nonrewarded trials whereas PA depends on carryover from both, one could account for a PA-PREE dissociation in this way. Another explanation has been advanced by Mackintosh (1971), who argued that dissociations of alternation and the PREE reflect conditioning to "imprecise aftereffects." Rats, in effect, cannot remember the immediately preceding nonrewarded trial, but they can remember that nonrewarded trials have occurred. Neither of these arguments, however, also predicts the absence of an effect of N-length on extinction, and therefore neither provides a good account of the present data.

The only way to produce a PREE, but not PA or an effect of $\mathbf{N}$-length, in a way that is consistent with sequential theory, is to employ a small number of training trials (Capaldi, 1967). Sequential theory states that $\mathrm{N}$-length influences extinction only after sufficient acquisition training. How much training? An effect of $\mathrm{N}$-length on extinction was obtained by Weinstock (1954) after 75 acquisition trials, by Bacon (1962) perhaps after 30 and certainly after 100 acquisition trials, and by Tyler, Wortz, and Bitterman (1953) after 120 acquisition trials. Infant rats do not differ from adults in the rate of acquisition (Amsel \& Stanton, 1980). Since the present study, of course, employed 120 acquisition trials, it is unlikely that the failure of $\mathrm{N}$-length to ir.fluence extinction reflects insufficient acquisition training. It is more likely that sequential mechanisms do not operate at the 105-sec ITI in the present study. That the absence of PA occurs in conjunction with an absence of an effect of $\mathbf{N}$-length on extinction is, in ract, consistent with sequential theory.

In a recent review of the ontogeny of appetitive instrumental learning (Amsel \& Stanton, 1980), it was noted that the PREE is present at an earlier point in development than are other paradoxical instrumental extinction effects. This ontogenetic pattern of results is hard to understand in terms of existing theories of instrumental learning (e.g., Amsel, 1967; Capaldi, 1967), at least if they are considered singly. However, Amsel and Stanton (1980) hypothesized that this apparent anomaly could be understood in terms of the two theories together by assuming that in early infancy the PREE is a massed-trials or "sequential" PREE, and is followed later in ontogeny by the spaced-trials or "frustrative" PREE and the other paradoxical effects. The present report fails to support this hypothesis by showing that the infant PREE can be obtained under trial-spacing conditions which appear to preclude the formation of sequential associations.

The existence of a spaced-trial PREE early in development was suggested by previous experiments from this laboratory. The PREE was obtained at 19-20 days of age with an ITI of about $15 \mathrm{~min}$ (Chen \& Amsel, 1975) and at 14 days of age with an ITI of 8-12 min (Letz et al., 1978). The recent finding that 14-day-old rats fail to show patterned alternation at ITIs that exceed $30 \mathrm{sec}$ (Stanton, 1982) suggests that the PREE reported by Letz et al. (1978) was of the spaced-trials variety. This dissociation of PA and the PREE, however, depends on comparisons across separate experiments involving similar, but not identical, procedures. Even if this were not a problem, some of the alternative interpretations of PA-PREE dissociations (see above) could still be advanced. The novel contribution of the present experiment has been (1) to define what constitutes a "spaced trial" for developing rats, not only in terms of pattern alternation, but in terms of the effect of N-length on extinction, and (2) to show, in the same experiment, a PREE under these "spaced-trial" conditions

The ontogeny of the paradoxical effects remains to be explained. Recent experiments from this laboratory have encouraged a shift in perspective on this issue (Chen et al., 1981; Stanton, Lobaugh, \& Amsel, in press). In particular, the finding that simultaneous contrast, a paradoxical effect found in discrimination learning, emerges between 11 and 14 days of age, makes the PREE no longer unique as an early appearing paradoxical effect. The simultaneous contrast data also show that the first appearance in ontogeny of this paradoxical effect is directly correlated with the first appearance of (independently defined and measured) frustrative reactions to the less favorable reward condition. This is the first demonstration of conditioned frustration at these early ages in terms of a paradoxical effect other than the PREE. Thus, the implication of the present experiments that the infant PREE reflects mechanisms postulated by frustration theory has some independent support.

Instead, the question becomes one of why the PREE and simultaneous contrast give evidence of conditioned frustration so much earlier in ontogeny than the other paradoxical effects we have examined. The former paradoxical effects seem to have the common feature that they depend on intermittent, trial-to-trial contrasts of, or shifts in, reward, whereas the latter effects (e.g., SNC, MREE, OEE) all involve con- 
trasts of reward across successive phases of training. In order to explain this pattern of results in the context of frustration theory, one could hypothesize that the successive-phase paradoxical effects require greater amounts of conditioned frustration than does simultaneous contrast or the PREE, and that the strength of conditioned frustration increases with age (see Amsel \& Stanton, 1980, p. 266). Such a hypothesis could be most explicitly stated by means of a mathematical model of frustration (Daly \& Daly, 1982). Further work is needed to confirm this hypothesis. For the time being, the fact remains that paradoxical effects involving phase shifts in reward develop later than those involving reward intermittency. Existing theories of instrumental extinction (Amsel, 1958; Capaldi, 1967) cannot account for this ontogenetic dissociation either alone or together.

\section{REFERENCES}

Amsel, A. The role of frustrative nonreward in noncontinuous reward situations. Psychological Bulletin, 1958, 55, 102-119.

Amse L, A. Frustrative nonreward in partial reinforcement and discrimination learning: Some recent history and a theoretical extention. Psychological Review, 1962, 69, 306-328.

Amse L, A. Partial reinforcement effects on vigor and persistence: Advances in frustration theory derived from a variety of withinsubjects experiments. In K. W. Spence \& J. T. Spence (Eds.), The psychology of learning and motivation (Vol. 1). New York: Academic Press, 1967.

Amsel, $A$. The ontogeny of appetitive learning and persistence in the rat. In N. E. Spear \& B. A. Campbell (Eds.), Ontogeny of learning and memory. Hillsdale, N.J: Erlbaum, 1979.

Amsel, A., \& Stanton, M. Ontogeny and phylogeny of paradoxical reward effects. In J. S. Rosenblatt, R. A. Hinde, C. Beer, \& M. Busnel (Eds.), Advances in the study of behavior. New York: Academic Press, 1980.

Bacon, W. E. Partial reinforcement extinction effect following different amounts of training. Journal of Comparative and Physiological Psychology, 1962, 55, 998-1003.

BIRCH, D. A motivational interpretation of extinction. In $\mathbf{M}$. R. Jones (Ed.), Nebraska symposium on motivation: 1961. Lincoln: University of Nebraska Press, 1961.

Bitte rman, M. E. The comparative analysis of learning. Science, 1975, 188, 699-709.

Burdette, D. R., Brake, S., Chen, J., \& Amsel, A. Ontogeny of persistence: Immediate extinction effects in preweanling and weanling rats. Animal Learning \& Behavior, 1976, 4, 131-138.

Campbell, B. A., \& Spear, N. E. Ontogeny of memory. Psychological Review, 1972, 79, 215-236.

CAPALd, E. J. A sequential hypothesis of instrumental learning. In K. W. Spence \& J. T. Spence (Eds.), The psychology of learning and motivation (Vol. 1). New York: Academic Press, 1967.

Capaldi, E. J. Memory and learning : A sequential viewpoint. In W. K. Honig \& P. H. R. James (Eds.), Animal memory. New York: Academic Press, 1971.

Chen, J., \& Amsel, A. Durability and retention of persistence acquired by young and infant rats. Journal of Comparative and Physiological Psychology, 1975, 89, 238-245.

Chen, J., \& Amsel, A. Learned persistence at 11-12 but not at 10-11 days in infant rats. Developmental Psychobiology, 1980, 13, 481-491.

Chen, J., Gross, K., \& Amsel, A. Ontogeny of successive negative contrast and its dissociation from other paradoxical reward effects in preweanling rats. Journal of Comparative and Physiological Psychology, 1981, 95, 146-159.
Couvillon, P. A., \& Bitterman, M. E. Analysis of alternation patterning in goldfish. Animal Learning \& Behavior, 1981, 9, 169-172.

DALY, H. B., \& DAly, J. T. A mathematical model of reward and aversive nonreward: Its application in over 30 appetitive learning situations. Journal of Experimental Psychology: General, 1982, 111, $441-480$.

Gonzalez, R. C. Patterning in goldfish as a function of magnitude of reinforcement. Psychonomic Science, 1972, 28, 53-55.

Gonzalez, R. C., Champlin, G. Positive behavioral contrast, negative simultaneous contrast and their relation to frustration in pigeons. Journal of Comparative and Physiological Psychology, 1974, 87, 173-187.

Gonzalez, R. C., Fernhoff, D., \& David, F. G. Contrast, resistance to extinction, and forgetting in rats. Journal of Comparative and Physiological Psychology, 1973, 84, 572-581.

Gray, J., Owens, S., Davis, N., \& Feldon, J. Associative and non-associative mechanisms in the development of tolerance for stress. In S. Levine \& H. Ursin (Eds.), Coping and health. New York: Plenum Press, 1980.

Hall, W. G., \& RosenelatT, J. S. Suckling behavior and intake control in the developing rat pup. Journal of Comparative and Physiological Psychology, 1977, 91, 1232-1247.

HuLL, C. L. Principles of behavior. New York: Appleton-CenturyCrofts, 1943.

Ison, J. R. Experimental extinction as a function of number of reinforcements. Journal of Experimental Psychology, 1962, 64, 314-317.

Letz, R., Burdette, D. R., Grega, B., Kittrell, M. E., \& Amsel, A. Evidence for a transitional period for the development of persistence in infant rats. Journal of Comparative and Physiological Psychology, 1978, 92, 856-866.

Mackintosh, N. J. Reward and aftereffects of reward in the learning of goldfish. Journal of Comparative and Physiological Psychology, 1971, 76, 225-232.

Mackintosh, N. J. The psychology of animal learning. London: Academic Press, 1974.

Rescorla, R. A., \& Wagner, A. R. A theory of Pavlovian conditioning: Variations in the effectiveness of reinforcement and nonreinforcement. In A. J. Black \& W. F. Prokasy (Eds.), Classical conditioning II: Current research and theory. New York: Appleton-Century-Crofts, 1972.

Stanton, M. E. Effect of trial spacing on the ontogeny of patterned alternation learning in the rat. Unpublished doctoral dissertation, University of Texas at Austin, 1981.

Stanton, M. E. Performance of 11- and 14-day-old rats on a working memory problem. Behavioral and Neural Biology, $1982,36,304-310$.

Stanton, M., \& Amsel, A. Adjustment to reward reduction (but no negative contrast) in rats 11,14 , and 16 days of age. Journal of Comparative and Physiological Psychology, 1980, 94, 446-458.

Stanton, M., Dailey, W., \& Amsel, A. Patterned (single) alternation in 11- and 14-day-old rats under various reward conditions. Journal of Comparative and Physiological Psychology, $1980,94,459-471$.

Stanton, M. E., Lobauah, N., \& Amsel, A. The age of first appearance of simultaneous and successive negative contrast in infant rats. Journal of Experimental Psychology: Animal Behavior Processes, in press.

Tyler, D. W., Wortz, E. C., \& Bitterman, M. E. The effect of random and alternating partial reinforcement on resistance to extinction in the rat. American Journal of Psychology, 1953, 66, 37-65.

WEINSTOCK, S. Resistance to extinction of a running response following partial reinforcement under widely spaced trials. Journal of Comparative and Physiological Psychology, 1954, 47, 318-322.

(Manuscript received March 18, 1983; revision accepted for publication July 19, 1983.) 